\title{
The mechanism of hamstring injuries - a systematic review
}

\author{
Adam Danielsson 1,2, Alexandra Horvath ${ }^{3}$, Carl Senorski', Eduard Alentorn-Geli ${ }^{4,5,6}$, William E. Garrett ${ }^{7}$, \\ Ramón Cugat ${ }^{4,5,6}$, Kristian Samuelsson ${ }^{1,2}$ and Eric Hamrin Senorski ${ }^{2,8^{*}}$ (D)
}

\begin{abstract}
Background: Injuries to the hamstring muscles are among the most common in sports and account for significant time loss. Despite being so common, the injury mechanism of hamstring injuries remains to be determined.

Purpose: To investigate the hamstring injury mechanism by conducting a systematic review.

Study design: A systematic review following the PRISMA statement.

Methods: A systematic search was conducted using PubMed, EMBASE and the Cochrane Library. Studies 1) written in English and 2) deciding on the mechanism of hamstring injury were eligible for inclusion. Literature reviews, systematic reviews, meta-analyses, conference abstracts, book chapters and editorials were excluded, as well as studies where the full text could not be obtained.

Results: Twenty-six of 2372 screened original studies were included and stratified to the mechanism or methods used to determine hamstring injury: stretch-related injuries, kinematic analysis, electromyography-based kinematic analysis and strength-related injuries. All studies that reported the stretch-type injury mechanism concluded that injury occurs due to extensive hip flexion with a hyperextended knee. The vast majority of studies on injuries during running proposed that these injuries occur during the late swing phase of the running gait cycle.

Conclusion: A stretch-type injury to the hamstrings is caused by extensive hip flexion with an extended knee. Hamstring injuries during sprinting are most likely to occur due to excessive muscle strain caused by eccentric contraction during the late swing phase of the running gait cycle.
\end{abstract}

Level of evidence: Level IV

Keywords: Running, Sprinting, Biomechanics, Strength, Muscle injury

\footnotetext{
* Correspondence: eric.hamrin.senorski@gu.se

${ }^{2}$ Department of Orthopaedics, Institute of Clinical Sciences, Sahlgrenska

Academy, University of Gothenburg, Göteborgsvägen 31, SE-431 80 Mölndal,

Gothenburg, Sweden

${ }^{8}$ Department of Health and Rehabilitation, Institute of Neuroscience and

Physiology, Sahlgrenska Academy, University of Gothenburg, Gothenburg,

Sweden

Full list of author information is available at the end of the article
}

(c) The Author(s). 2020 Open Access This article is licensed under a Creative Commons Attribution 4.0 International License, which permits use, sharing, adaptation, distribution and reproduction in any medium or format, as long as you give appropriate credit to the original author(s) and the source, provide a link to the Creative Commons licence, and indicate if changes were made. The images or other third party material in this article are included in the article's Creative Commons licence, unless indicated otherwise in a credit line to the material. If material is not included in the article's Creative Commons licence and your intended use is not permitted by statutory regulation or exceeds the permitted use, you will need to obtain permission directly from the copyright holder. To view a copy of this licence, visit http://creativecommons.org/licenses/by/4.0/. The Creative Commons Public Domain Dedication waiver (http://creativecommons.org/publicdomain/zero/1.0/) applies to the data made available in this article, unless otherwise stated in a credit line to the data. 


\section{Background}

Hamstring injuries are common in several sports, with an overall incidence of 1.2-4 injuries per $1000 \mathrm{~h}$ of athlete exposure [1-3]. In athletics and Gaelic football, they account for $17-21 \%$ of total injuries [3, 4] and it is suggested that approximately $22 \%$ of all football players sustain a hamstring injury each season [1]. Hamstring injuries result in an average time loss of 24 days [5] and, result in high cost for professional athletes and teams [6]. Furthermore, dancers exhibit a high incidence of muscle injuries [7]. The relevance of hamstring injuries in sports is therefore paramount.

A growing body of research has focused on hamstring injuries, specifically to identify risk factors [8-10] and to develop prevention and rehabilitation programmes [1115]. However, there is no consensus on hamstring injury mechanism. Askling et al. [16] proposed two scenarios in which a hamstring injury may occur; during either highspeed running, or stretching movements [16]. The highspeed running type of injury typically affects the long head of the biceps femoris (BFlh) and has a shorter recovery time than the stretching type of injury, which commonly affects the semimembranosus (SM) [17-19]. The running type of injury is the most frequent $[20,21]$ and, in Australian football, $81 \%$ of hamstring injuries occur during sprinting, while kicking (stretching type) accounts for $19 \%$ of injuries [2]. In the literature, there are two theories on the mechanism of hamstring injuries sustained during running. One is based on the findings of Garret and Lieber et al. [22, 23], who believed that the hamstring is most susceptible to injury during active lengthening, typically observed during the late swing phase of the running gait cycle (Fig. 1) [24]. As a result, preventive studies have focused on eccentric strengthening, with, for example, the Nordic hamstring exercise, which is associated with a significantly lower injury incidence [25-27]. Mann et al. [28], however, proposed that hamstring injury occurs during the initial stance phase because of the large forces in opposing directions as the body is propelled forward over the touchdown point (Fig. 1). By defining the mechanism of injury, new preventive strategies can hopefully be created to help reduce the number of hamstring injuries and re-injuries among athletes and patients. The aim of this study was to investigate the hamstring injury mechanism in a systematic review.

\section{Methods}

The methodology of this study was reported following the Preferred Reporting Items for Systematic Reviews and Meta-Analyses (PRISMA) statement [29].

\section{Eligibility criteria}

All the original studies that investigated the mechanism of hamstring injury or the biomechanical properties of the hamstrings were evaluated for eligibility. Hamstring injury was defined as a strain injury to the hamstring muscle group. Therefore, hamstring injuries with avulsion fractures were not considered for this systematic review. Studies were included if 1) they were written in English and; 2) conclusions were extrapolated on the mechanisms of hamstring injury. Literature reviews, systematic reviews, meta-analyses, conference abstracts, chapters from text-books and

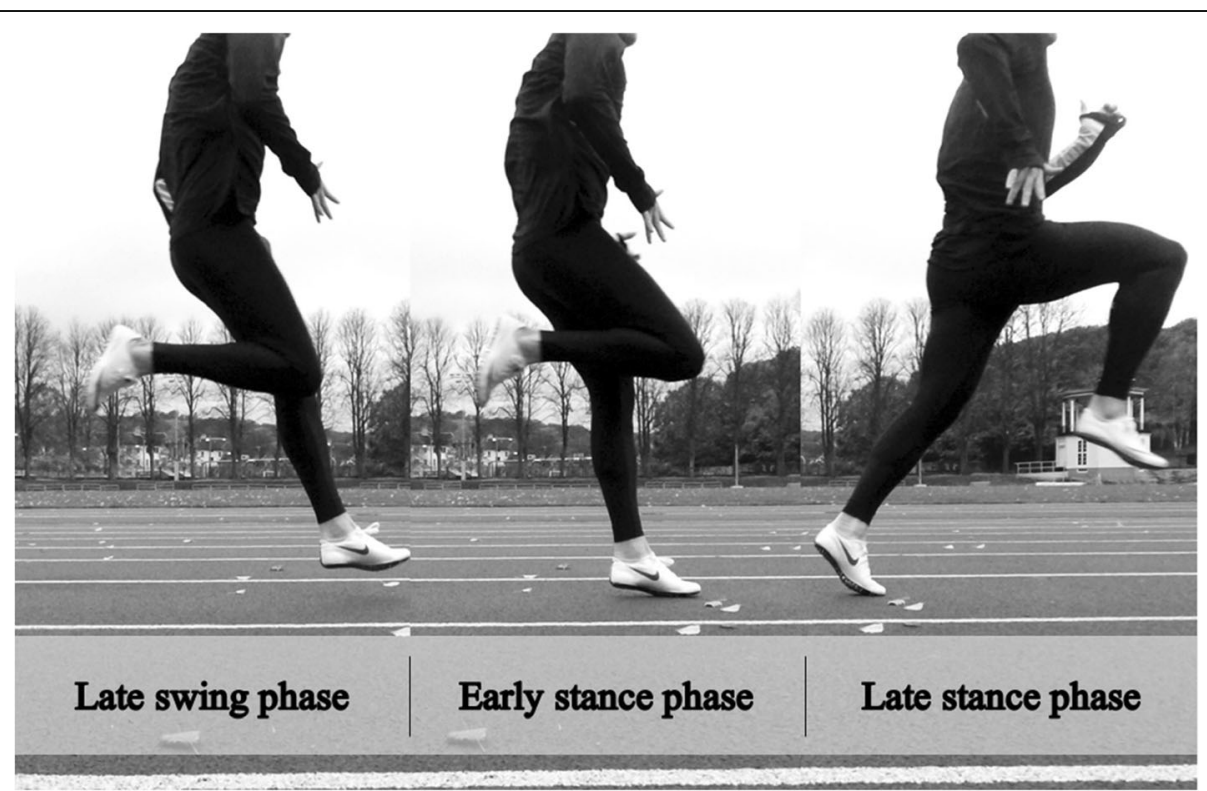

Fig. 1 The running gait cycle 
editorials were excluded, as well as studies where the full text could not be obtained.

\section{Information sources and search Electronic search}

A systematic electronic literature search was conducted on 21 February 2017 using the PubMed (first available date), EMBASE (starting in 1974) and the Cochrane Library (first available date) databases by an expert in electronic searching. An updated search was performed on 30 May 2018 for the PubMed and Cochrane, while an EMBASE search was updated on 7 June 2018. A third search was carried out on 10 July 2019. For all databases, a similar search strategy was used, where the only differences were due to database configuration. The search strategies used a combination of Medical Subject Heading (MeSH) terms and "title/abstract" search. The search strategy consisted of "hamstring AND injury NOT anterior cruciate ligament", including synonyms (Tables 5, 6, 7 in Appendix).

\section{Other search methods}

The reference lists of all studies read in full text were screened for potential studies not previously identified.

\section{Data collection and analysis \\ Study selection}

All titles and abstracts were read and studies of potential interest were reviewed in full text independently by two authors (Author 1 and Author 2) to decide on inclusion or exclusion. Disagreements were resolved through discussion with senior authors (Author 7 and Author 8).

\section{Data collection process}

The data extraction process was performed in duplicate (Author 1 and Author 2) using a piloted form of a Microsoft Excel (Microsoft, USA) spreadsheet and the following parameters were retrieved; author, year of publication, title, journal, number of study subjects, information on study subjects (age, sex) purpose, a detailed description of the methods used to assess injury mechanism (including important details such as the use of a treadmill or track, surface or needle electrodes, sampling rate if performing a video analysis, the use of reflective markers and/or force plates to measure ground reaction force), a summary of the results and the authors' conclusions.

\section{Data synthesis}

The data synthesis was performed with a qualitative approach by gathering the authors' results and conclusions, thereby excluding studies in which the hypothesised, suggested hamstring injury mechanism was not presented. Groups were created during the review process based on the common study methods used and different injury mechanisms reported. These groups are presented as stretch-related injuries, kinematic analysis, electromyograph-based kinematic analysis and strength-related injuries respectively.

\section{Quality appraisal of included studies}

The included studies were evaluated for their reporting quality using the Downs and Black Checklist [30] comprising 27 items. Ten of the items refer to the reporting of study results, three items refer to external validity, 13 items to internal validity and one item to power calculation. Since none of the included studies was interventional and only one study had comparative groups, a total of 16 items were used, while 11 were excluded from the qualitative analysis (items $4-5,8,13-15,19,21-24)$. Of the 16 items used, seven examined the reporting of information, two examined external validity, six investigated internal validity and one item was related to power calculation. Each item can be answered yes ( 1 point), no ( 0 points) and unable to determine (0 points), except item 27, which may yield up to five points depending on the power calculation. The maximum score on the modified Down and Blacks Checklist is 20. However, not all of the 16 included items were applicable to each individual study, as study methodologies differed. Two authors (Author 1 and Author 2) independently performed the quality appraisal and differences were resolved with discussion (Table 8 in Appendix).

\section{Results \\ Study selection}

The database search identified 318 studies from the Cochrane Library, 2053 from EMBASE and 1893 from PubMed, giving a total of 4264 studies. After the removal of the 1423 duplicates, the remaining 2841 studies were screened by abstract and title. Eligible studies underwent full text assessment and 21 studies were included in the final systematic review. During the full text assessment, 52 previously unidentified studies were identified from the reference lists (Fig. 2), of which five studies were eligible for inclusion [19, 28, 31-33].

\section{Risk of bias assessment}

The quality appraisal with a modified version of the Downs and Black Checklist [30] resulted in a median (range) score of $8(7-14)$ points of 20 possible. See Table 1 for full results. 


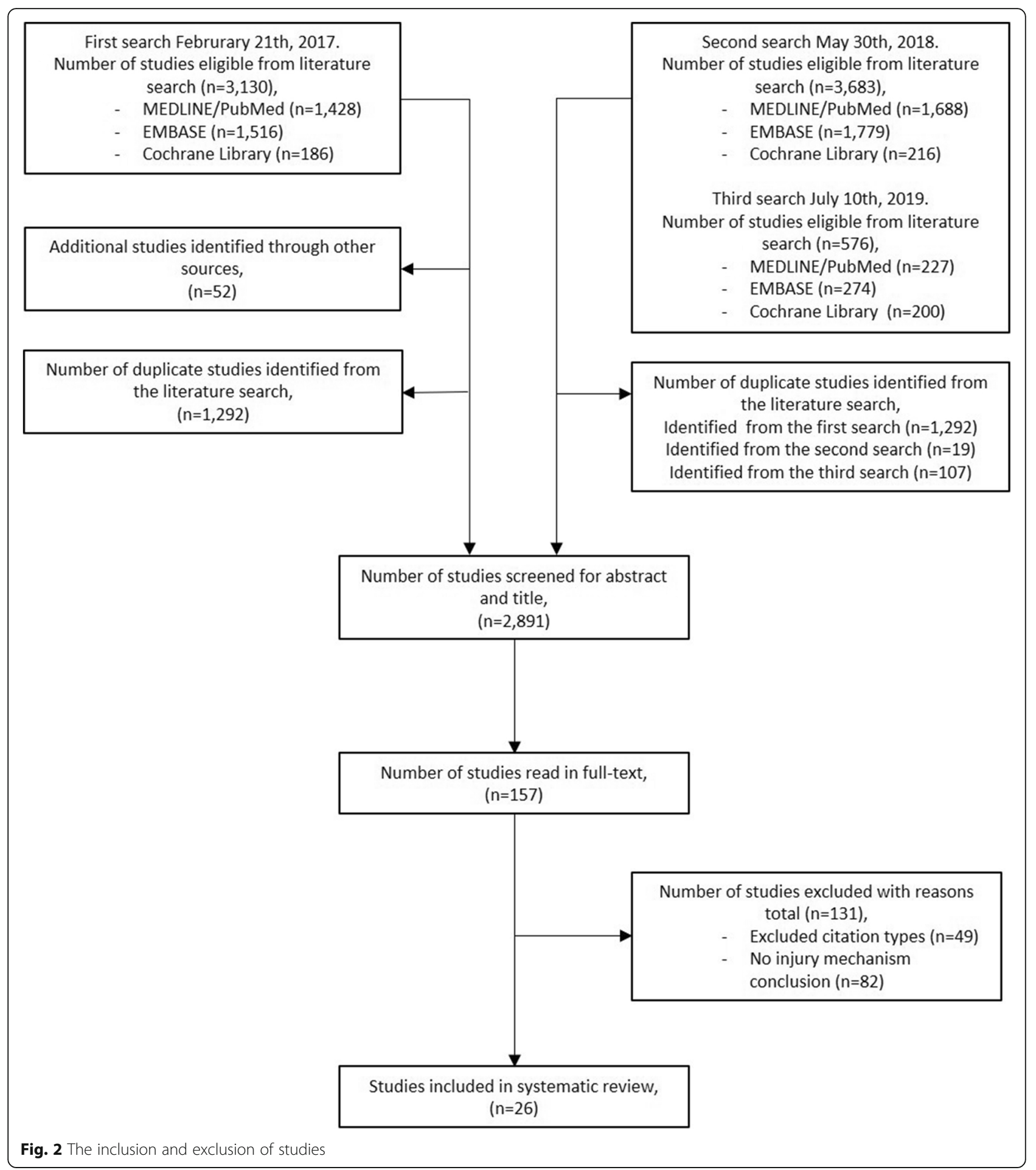

\section{Characteristics of included studies}

Of the 26 studies included, three investigated stretchtype hamstring injuries [19, 31, 45], 10 performed a kinematic analysis [28, 32, 35, 37, 39, 46, 47, 51-53], 10 additional studies performed a kinematic analysis combined with an electromyographic (EMG) analysis $[33,34,36,38,41-44,48,54]$ and three analysed muscle strength $[40,49,50]$. The number of participants in the included studies ranged from one to 54 (total of 444 participants; some individuals included in more than one study) with an age range of 16-53 years.

Six studies analysed actual hamstring injuries [19, 31, 37, 45-47], one study compared previously injured and 


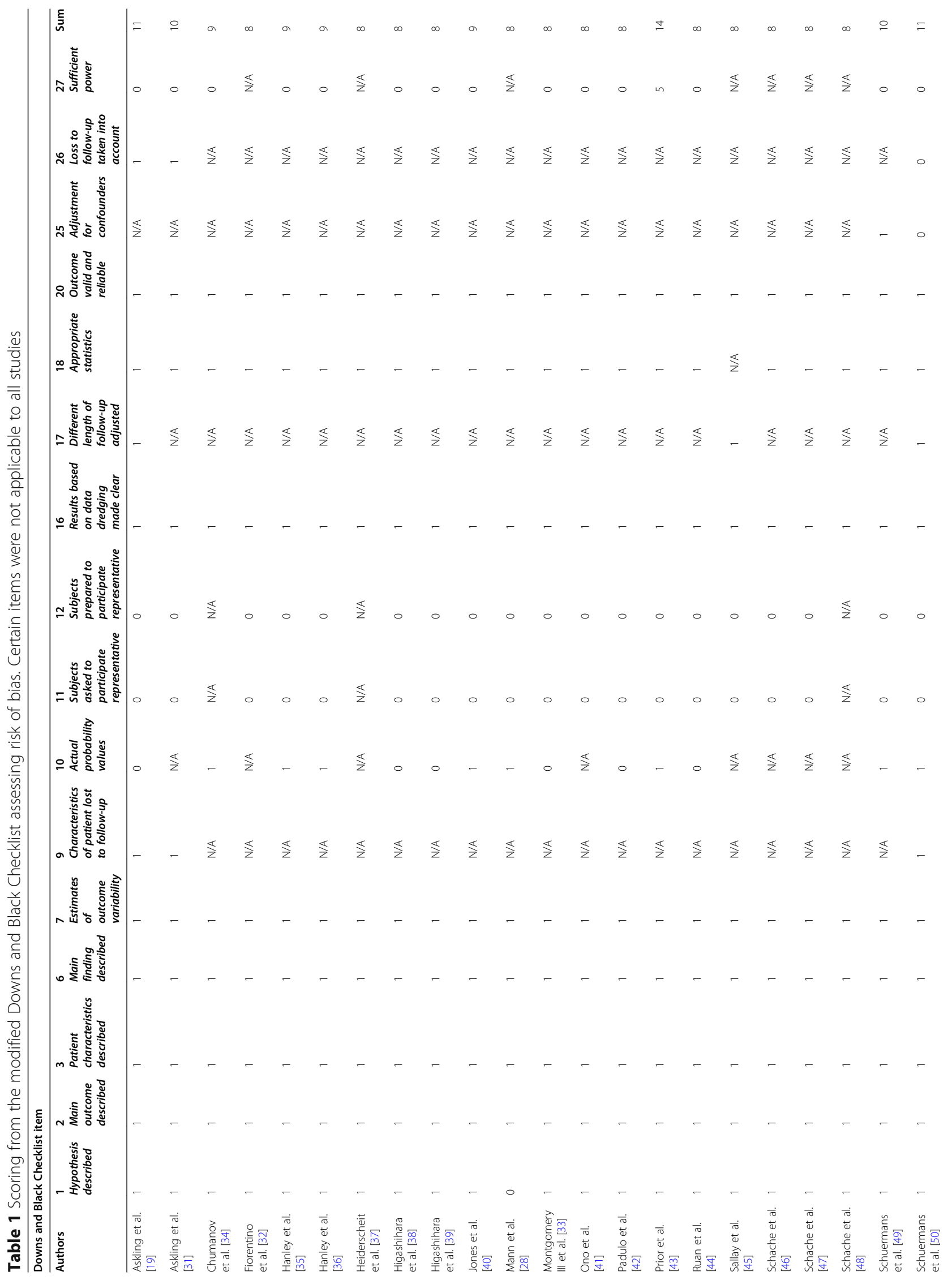




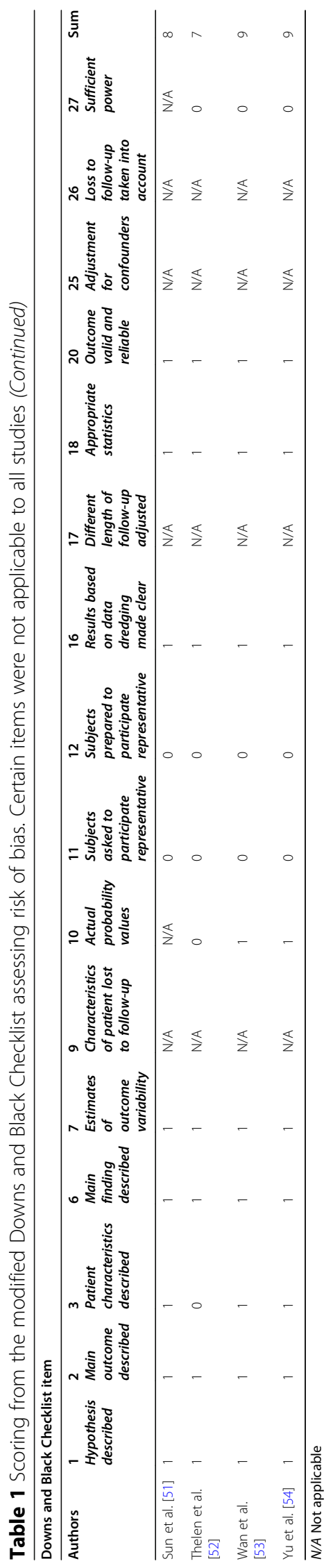


uninjured individuals [49], while 19 studies performed the analyses on uninjured individuals and estimated the hamstring injury mechanism [28, 32-36, 38-44, 48, 5054]. A summary of the suggested hamstring injury mechanisms is presented in Table 2 and a comprehensive summary of the included studies can be found in Table 9 in Appendix.

\section{Stretch-related hamstring injuries}

Three studies investigated hamstring injuries in dancers and water skiers and scored a median (range) of 10 points $(8-11)$ out of 20 possible on the modified Downs and Black Checklist. The study populations ranged from 12 to 30 subjects aged $16-53$ years who participated in interviews and clinical and magnetic resonance imaging (MRI)) examinations to determine the hamstring injury mechanism. All three studies reported that hamstring injuries occurred due to extensive hip flexion with a hyperextended knee $[19,31,45]$. In one study of dancers, the quadratus femoris and adductor magnus were injured simultaneously with the hamstrings [19].

\section{Hamstring injury mechanism from kinematic analysis}

Ten studies investigated the hamstrings through a kinematic analysis of study subjects aged $16-31$ years with a median (range) score of 8 (7-9) of 20 possible on the modified Downs and Black Checklist. Nine of these studies were conducted on runners $[28,32,37,39$, $46,47,51-53$ ] and one on race walkers [35]. with study populations ranging from one to 20 participants. High-speed cameras and skin-placed markers

Table 2 Summary of the suggested hamstring injury mechanisms and most injury-prone phase stratified by results and method used to investigate injury mechanism

\begin{tabular}{ll}
\hline $\begin{array}{l}\text { Results according to injury mechanism and study } \\
\text { method }\end{array}$ & $\begin{array}{l}\text { Number of } \\
\text { studies }\end{array}$ \\
\hline Stretch-type injury & 3 \\
Hyperextension $[19,31,45]$ & 3 \\
Kinematics & 10 \\
Swing phase [32, 35, 37, 46, 47, 52, 53] & 7 \\
Stance phase [28, 39] & 2 \\
Both phases [51] & 1 \\
Kinematics with electromyographic analysis & 9 \\
Swing phase [33, 34, 36, 38, 48] & 5 \\
Stance phase [41] & 1 \\
Two phases [44, 54] & 2 \\
Other [42, 43] & 2 \\
Strength & 3 \\
Fatigue [40, 49] & 2 \\
Asymmetrical activation [50] & 1 \\
\hline
\end{tabular}

on anatomic landmarks were most commonly used to study the injuries while the subjects ran on a treadmill or track. In four studies, a force plate was added to obtain additional information [35, 46, 47, 51]. One study measured BFlh dimensions using MRI images which were subsequently used in a simulation of hamstring injury mechanics [32]. Three studies were able to record a hamstring injury in real time [37, 46, 47]. However, two of these studies based their conclusions on data from the same study subject [46, 47]. Seven studies made estimations of where the hamstrings were at highest risk of injury $[28,32,35,39$, 51-53].

Two studies reported that hamstring injuries occur during the early stance phase [28, 39], while running with a forward trunk lean [39]. In contrast, seven studies concluded that hamstring injuries occur during the swing phase [32, 35, 37, 46, 47, 52, 53] and one study concluded that both phases exhibit a risk of injury [51]. It was proposed that the late or terminal swing phase placed the hamstring muscles at the highest risk of injury (Table 3).

\section{Hamstring injury mechanism from kinematic and electromyographic analysis}

Ten studies performed EMG-based kinematic analysis $[33,34,36,38,41-44,48,54]$ measured with either surface or needle electrodes [33] and, in some cases, with additional force plates [36, 41, 48]. The modified Downs and Black Checklist yielded a total median (range) score of $8(8-14)$ of 20 possible for these studies. Seven studies analysed runners [33, 34, 38, 41, 44, 48, 54], one study used race walkers [36], one evaluated volleyball players performing different jumping tasks [42] and one study compared muscle activity while standing on one leg with different trunk and pelvic positions in healthy volunteers [43]. The studies included recreational and high-level athletes with an age range of 18-53 years and consisted of seven to 30 individuals.

One study concluded that the risk of hamstring injury is greatest during the early stance phase [41], while five studies reported that injury occurred during the swing phase $[33,34,36,38,48]$. One study suggested that hamstring injury may occur during either the early stance phase or late swing phase [44], while another study reported that injury could occur during both the late stance and late swing phase (Fig. 1) [54].

One study reported that anterior trunk sway and contralateral pelvic drop while standing on one leg increased the load on the hamstrings [43], while another study reported that the hamstrings are at risk of injury during concentric, braking movements [42]. All conclusions were based on estimations of when 


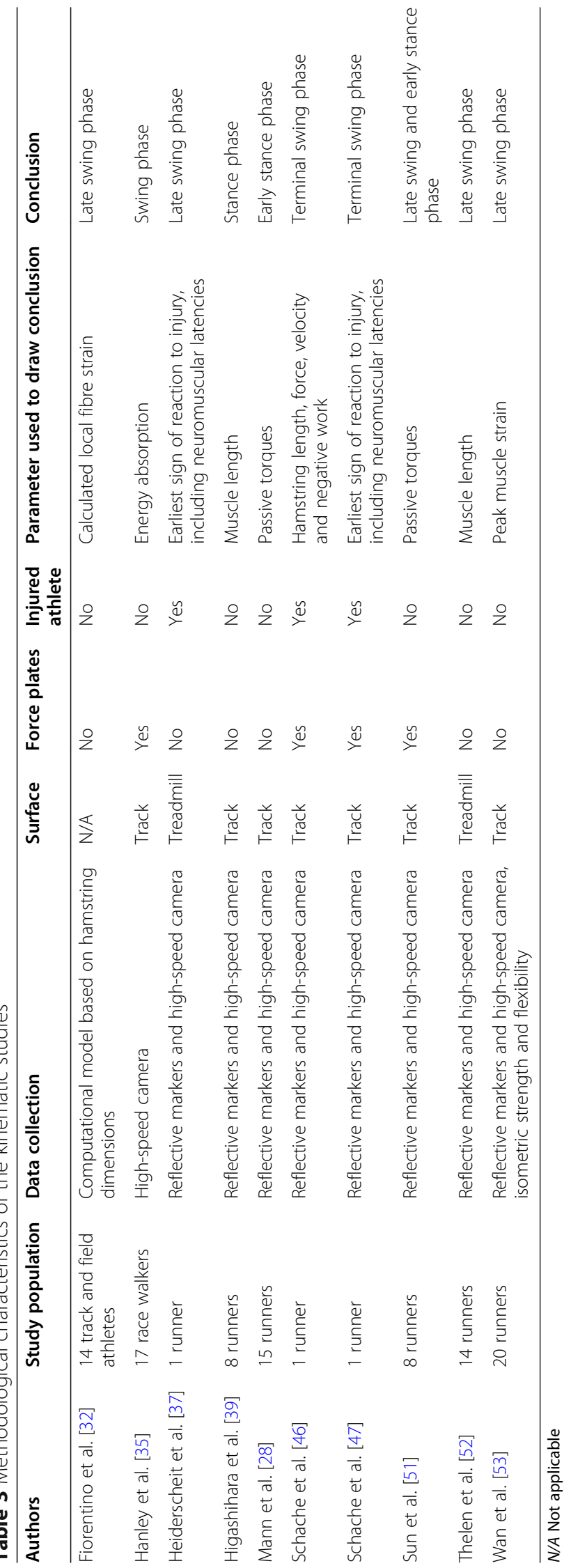


the highest risk of hamstring injury occurs, i.e. no study included an actual hamstring injury (Table 4).

\section{Strength-related hamstring injuries}

Three studies investigated hamstring strength in football players aged $18-35$ years $[40,49,50]$ and scored a median (range) value of 10 points (9-11) of 20 possible on the modified Downs and Black Checklist. One study measured seated isokinetic strength in 20 football players prior to, during and after an exercise protocol set to simulate the muscle fatigue induced by a football game [40]. It was reported that hamstring injury was caused by lower eccentric strength due to fatigue [40]. Two studies used muscle functional magnetic resonance imaging (mfMRI) to compare metabolic activity before and after an eccentric hamstring exercise in previously uninjured and injured football players [49, 50]. One study reported that previously injured athletes had lower eccentric endurance of the hamstrings compared with uninjured athletes. It was proposed that the inferior hamstring endurance was a result of less economic muscle activation which may constitute a risk for injury [49]. One study performed an MRI analysis before and after an eccentric hamstring exercise and registered hamstring injuries for the following 1.5 seasons [50]. The results indicated that a greater contribution from the biceps femoris compared with the semitendinosus (ST) during an eccentric hamstring exercise correlates with first-time hamstring injuries. Re-injuries were associated with lower eccentric hamstring endurance [50].

\section{Discussion}

Across studies that investigated runners, the most commonly suggested injury mechanism was eccentric strain during the late swing phase of the running gait cycle. In a sub-group of hamstring injuries, the reviewed studies reported that the mechanism of hamstring injuries includes a simultaneous hip flexion and knee extension.

\section{Stretch-related hamstring injuries}

All the studies [19, 31, 45] of stretch-type injuries concluded that injuries occur due to extensive hip flexion with simultaneous knee extension. The study methods were similar, with a qualitative interview on the injury situation as the main source of information. In Australian football, a total of 19\% of hamstring injuries occur during kicking [2], which is a typical stretch-type hamstring injury, given that the end of a kick exhibits both a flexed hip and extended knee position. In addition, Worth [55] suggested that trying to pick up a ball from the ground while running at full speed is the most common hamstring injury situation in Australian football. Picking up something from the ground may exhibit the same traits as the stretch-type hamstring injuries, further supporting this theory [55]. Notably, these studies analysed patients who had sustained hamstring injuries. However, since none of the hamstring injuries was observed by the researchers, the injury situations were recalled by the patient, thereby entailing a risk of bias. The findings relating to stretch-type hamstring injury should therefore be interpreted with caution.

\section{Hamstring injuries during running}

The majority of studies of hamstring injuries during running reported that the hamstrings are most prone to injury during the late swing phase as a result of eccentric loading. However, some studies reported that the hamstrings are most likely to be injured during the stance phase. It is pivotal to acknowledge that, in cases in which an accidental hamstring injury was recorded in real time, the authors concluded that the injury occurred during the late swing phase $[37,46,47]$. This information was concluded through the earliest sign of injury including neuromuscular latencies $[37,47]$ as well as examining hamstring length, force, velocity and negative work [46]. This is in line with the findings of a recent literature review which suggests that hamstring injury during the late swing phase occurs due to high levels of muscle excitation and muscle strain [56]. Interestingly, Mendiguchia et al. [57] were able to record a hamstring injury and, while no injury mechanism was reported, the authors stated that the injury occurred when the subject ran with an "abnormal increase in power compared with velocity qualities" [57].

One study concluded that a hamstring injury is most likely to occur during the stance phase when comparing a normal running technique with a technique in which the subjects run with a forward trunk lean [39]. These results are in line with the findings of Prior et al. [43], who reported that an anterior trunk sway during single leg stance, similar to positions which occur in pivoting sports, increased hamstring strain [43]. However, strain on the hamstring muscles and injury conditions during running with a forward trunk lean may differ from a normal running technique as the forwards trunk lean elongates the hamstring muscle causing more strain. Interestingly, a forward trunk lean had the greatest impact during the stance phase with the knee fully extended, similar to the stretch-type injury mechanism. The forward trunk lean can be caused by poor activation and control of the muscles of the core and hip, thereby increasing the strain and injury risk of the hamstrings [58-61]. For this reason, an in-depth knowledge of this type of injury is imperative and could be implemented in hamstring injury prevention and rehabilitation programmes, focusing on hip and core strengthening exercises in addition to traditional hamstring exercises.

Furthermore, static stretching may reduce both the ground reaction forces observed in the early stance phase and the strain on the BFlh during the late swing phase [44]. This results in subsequent reduced peak values of joint torque at the hip and knee and increased force 


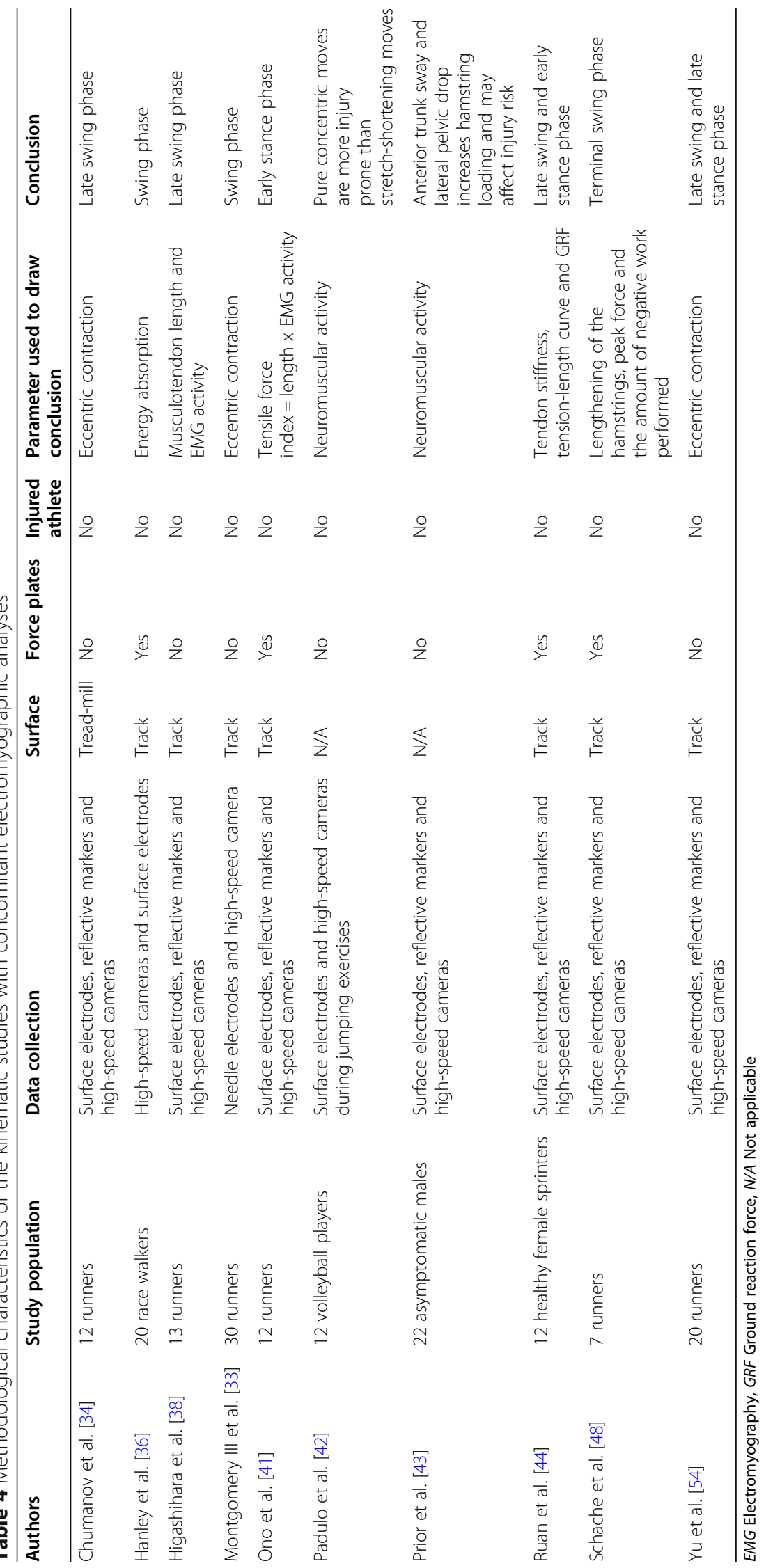


productions of the biceps femoris at longer muscle lengths, which demonstrates that stretching may reduce the risk of hamstring injuries $[44,56]$. These findings are of particular interest as preventive studies on the Nordic hamstring exercise which focuses on eccentric training have shown to reduce the risk of hamstring injuries [2527]. The preventive effect of the Nordic hamstring exercise may be attributed to its ability to increase muscle fascicle length [62] as short hamstring fascicles are associated with an increased risk of a hamstring injury [63].

The results of a study of muscle activity during running and preventive exercises for the hamstrings suggested that the highest activity of the hamstrings occurs during the late swing phase [64], potentially associated with an increased risk of injury. On the other hand, Ono et al. [41] reported that, during the swing phase, the tensile forces in the ST exceed the forces in the BFlh, while the BFlh during the stance phase demonstrates higher forces. Since it is more common to injure the BFlh while running compared with the ST, the authors suggested that hamstring injury probably occurs during the stance phase [18]. In addition, the medial hamstrings are primarily loaded during the swing phase, where the lateral hamstrings are active throughout the entire gait cycle [65], which may help to explain why the ST is less injured, despite the high force [41].

In the light of these findings, several limitations need to be mentioned. There were only three case reports that studied recordings of a real-time hamstring injury [37, $46,47]$ and the same study subject was used in two of the case reports $[46,47]$. Furthermore, contextual conditions varied between studies, where, in some studies, the running analyses were performed on a treadmill [34, 37, 52] and had subjects running at a slow pace, which may not reflect the mechanism of hamstring injury. Since hamstring injuries commonly affect athletes playing various sports on grass fields, there is a lack of studies examining the injury mechanism in those conditions. The results in current literature may therefore prove difficult to apply to hamstring injuries sustained on grass. In addition, some studies performed a kinematic analysis without the use of an EMG which, it can be argued, only investigates hamstring lengthening and not active lengthening, i.e. eccentric contraction, as muscle activity is not measured.

In conclusion, hamstring injuries sustained while running or sprinting are estimated to occur during the late swing phase as a consequence of increased strain on the hamstring muscles. However, further research is needed to confirm these findings.

\section{Strength-related hamstring injuries}

There are inconclusive results from retrospective studies of hamstring strength in relation to the mechanism of injury. Fatigue was reported to reduce eccentric hamstring strength, which was suggested to increase the risk of a hamstring injury [40], while lower hamstring strength endurance was associated with a hamstring reinjury [50]. One study compared muscle activity in athletes with previously injured and uninjured hamstrings and reported that the previously injured athletes had inferior hamstring activation, which contributes to lower hamstring strength [49]. These findings are most probably related to risk factors for suffering a subsequent injury, which may in turn help to improve rehabilitation, rather than being related to the mechanism of hamstring injury $[1,5,66]$.

\section{Limitations}

Most importantly, the majority of studies based their conclusions on estimations of the hamstring injury mechanism. Furthermore, the number of publications relating to the hamstring injury mechanism is limited and different methods have been used to assess the mechanism of injury. As a result, the included studies were allocated to groups defined by the study method and mechanism of injury. Each group included a limited number of studies with different methodological limitations which resulted in uncertainty about the results in this systematic review. In addition, a number of biomechanical studies were excluded, as no conclusions were drawn with regard to the hamstring injury mechanism. The extensive manual search of the reference lists of included studies helped to identify additional literature on the hamstring injury mechanism. However, the inclusion criterion of "conclusions were extrapolated by the authors with regard to the mechanisms of hamstring injury" may have introduced bias, as studies either estimated the mechanism of injury or retrospectively reviewed hamstring injuries and not an actual injury per se. Also, only studies written in English were set to be included but throughout the process of manually searching reference lists no studies were excluded for this reason.

The Downs and Black Checklist was deemed the most correct to determine the reporting quality of included studies, although it was not completely suited to the study designs included. The overall interpretation of reporting quality was low, with a risk of bias related primarily to study size and design, although there are no cut-offs or standardised methods for interpreting the modified version of the Downs and Black Checklist.

\section{Conclusion}

A stretch-type injury to the hamstrings is caused by extensive hip flexion with an extended knee. Hamstring injuries during sprinting are most likely to occur due to excessive muscle strain caused by eccentric contraction during the late swing phase of the running gait cycle. 


\section{Appendix}

Table 5 Search strategy PubMed

\begin{tabular}{|c|c|}
\hline \multicolumn{2}{|c|}{ Database: PubMed } \\
\hline \multicolumn{2}{|c|}{ Date: $2017-02-21$} \\
\hline \multicolumn{2}{|c|}{ Number of results: 1428 references } \\
\hline Search & Query \\
\hline$\# 6$ & Search \#3 NOT \#4 Filters: English \\
\hline$\# 5$ & Search \#3 NOT \#4 \\
\hline \#4 & $\begin{array}{l}\text { Search Anterior cruciate ligament[ti] OR patellar tendon[ti] OR } \\
\text { ACL[ti] OR posterior cruciate ligament[ti] }\end{array}$ \\
\hline \#3 & Search \#1 AND \#2 \\
\hline$\# 2$ & $\begin{array}{l}\text { Search "Wounds and Injuries"[Mesh:NoExp] OR "Athletic } \\
\text { Injuries"[Mesh] OR "Leg Injuries"[Mesh:NoExp] OR "Sprains and } \\
\text { Strains"[Mesh:NoExp] OR "Tendon Injuries"[Mesh:NoExp] OR } \\
\text { "injuries"[Subheading] OR injury[tiab] OR injuries[tiab] OR } \\
\text { tear[tiab] OR tears[tiab] OR rupture[tiab] OR strain[tiab] OR } \\
\text { strains[tiab] }\end{array}$ \\
\hline$\# 1$ & $\begin{array}{l}\text { Search "Hamstring Tendons"[Mesh] OR "Hamstring } \\
\text { Muscles"[Mesh] OR hamstring[tiab] OR hamstrings[tiab] }\end{array}$ \\
\hline \multicolumn{2}{|c|}{ Database: PubMed } \\
\hline \multicolumn{2}{|c|}{ Date: 2018-05-30 } \\
\hline \multicolumn{2}{|c|}{ Number of results: 1688 references } \\
\hline Search & Query \\
\hline$\# 1$ & $\begin{array}{l}\text { Search ("“Hamstring Tendons"[Mesh] OR "Hamstring } \\
\text { Muscles"[Mesh] OR hamstring[tiab] OR hamstrings[tiab]) AND } \\
\text { ("Wounds and Injuries"[Mesh:noexp] OR "Athletic } \\
\text { Injuries"[Mesh] OR "Leg Injuries"[Mesh:noexp] OR "Sprains and } \\
\text { Strains"[Mesh:noexp] OR "Tendon Injuries"[Mesh:noexp] OR } \\
\text { "injuries"[Subheading] OR injury[tiab] OR injuries[tiab] OR } \\
\text { tear[tiab] OR tears[tiab] OR rupture[tiab] OR strain[tiab] OR } \\
\text { strains[tiab])) NOT (Anterior cruciate ligament[ti] OR patellar } \\
\text { tendon[ti] OR ACL[ti] OR posterior cruciate ligament[ti]) Filters: } \\
\text { English }\end{array}$ \\
\hline
\end{tabular}

Database: PubMed

Date: 2018-05-30

Number of results: 1688 references

\begin{tabular}{|c|c|c|}
\hline Search & Query & $\begin{array}{l}\text { Items } \\
\text { found }\end{array}$ \\
\hline$\# 10$ & Search \#7 AND \#8 Filters: English & 200 \\
\hline \#9 & Search \#7 AND \#8 & 205 \\
\hline$\# 8$ & Search "2018/05/30"[crdt]: "2019/07/10"[crdt] & 1454534 \\
\hline$\# 7$ & Search \#5 NOT \#6 & 1960 \\
\hline$\# 6$ & $\begin{array}{l}\text { Search Anterior cruciate ligament[ti] OR patellar tendon[ti] OR } \\
\text { ACL[ti] OR posterior cruciate ligament[ti] }\end{array}$ & 15670 \\
\hline$\# 5$ & Search \#3 AND \#4 & 3156 \\
\hline \#4 & $\begin{array}{l}\text { Search "Wounds and Injuries"[Mesh:noexp] OR "Athletic } \\
\text { Injuries"[Mesh] OR "Leg Injuries"[Mesh:noexp] OR "Sprains and } \\
\text { Strains"[Mesh:noexp] OR "Tendon Injuries"[Mesh:noexp] OR } \\
\text { "injuries"[Subheading] OR injury[tiab] OR injuries[tiab] OR } \\
\text { tear[tiab] OR tears[tiab] OR rupture[tiab] OR strain[tiab] OR } \\
\text { strains[tiab] }\end{array}$ & 1687635 \\
\hline \#3 & $\begin{array}{l}\text { Search "Hamstring Tendons"[Mesh] OR "Hamstring } \\
\text { Muscles"[Mesh] OR hamstring[tiab] OR hamstrings[tiab] }\end{array}$ & 7710 \\
\hline
\end{tabular}

found

1428

1480

13007

2384

1483367

Items
found

1688
Table 6 Search Strategy EMBASE

Database: EMBASE 1974 to 2017 February 17

Date: 2017-02-21

Number of results: 1516 references

\# Search

Hits

exp hamstring/

6601

2 (hamstring or hamstrings).ab,ti.

7417

31 or 2

8479

109,627

4 *injury/

5 muscle injury/

6 leg injury/

7 exp tendon injury/

8 sport injury/

9 *musculoskeletal injury/ or sprain/

11,322

8177

20,052

27,033

4077

104 or 5 or 6 or 7 or 8 or 9

169,425

11 (injury or injuries or tear or tears or rupture or strain or strains).ab,ti.

1210 or 11

$13 \quad 3$ and 12

14 (Anterior cruciate ligament or patellar tendon or $\mathrm{ACL}$ or posterior cruciate ligament).ti.

$15 \quad 13$ not 14

6 limit 15 to (English and (article or conference paper or note or "review"))

1516

Database: EMBASE 1974 to 2018 June 7

Date: 2018-06-07

Number of results: 1779 references

\# Search

Hits

exp hamstring/

3723

2 (hamstring or hamstrings).ab,ti.

8371

10,897

1 or 2

*injury/

muscle injury/

leg injury/

7 exp tendon injury/

8 sport injury/

9 *musculoskeletal injury/ or sprain/

63,184

10,903

8268

20,447

27,738

3474

128,054

11 (injury or injuries or tear or tears or rupture

or strain or strains).ab,ti.

1,680 ,

755

1210 or 11

1,737 ,

093

3656

$13 \quad 3$ and 12

14 (Anterior cruciate ligament or patellar tendon

or $\mathrm{ACL}$ or posterior cruciate ligament).ti.

$15 \quad 13$ not 14

16,690

2324

16 limit $\mathbf{1 5}$ to (English and (article or conference paper or note or "review"))

1779

Database: EMBASE 1974 to 2019 July 9

Date: 2019-07-10

Number of results: 274 references

\# Search

Hits

1 exp hamstring/ 
Table 6 Search Strategy EMBASE (Continued)

\begin{tabular}{|c|c|c|}
\hline 2 & (hamstring or hamstrings).ab,ti. & 9410 \\
\hline 3 & 1 or 2 & 12,461 \\
\hline 4 & *injury/ & 59,371 \\
\hline 5 & muscle injury/ & 11,874 \\
\hline 6 & leg injury/ & 7328 \\
\hline 7 & exp tendon injury/ & 21,448 \\
\hline 8 & sport injury/ & 28,438 \\
\hline 9 & *musculoskeletal injury/ or sprain/ & 3831 \\
\hline 10 & 4 or 5 or 6 or 7 or 8 or 9 & 126,329 \\
\hline 11 & (injury or injuries or tear or tears or rupture or strain or strains).ab,ti. & $\begin{array}{l}1,771 \\
861\end{array}$ \\
\hline 12 & 10 or 11 & $\begin{array}{l}1,824 \\
435\end{array}$ \\
\hline 13 & 3 and 12 & 4260 \\
\hline 14 & $\begin{array}{l}\text { (Anterior cruciate ligament or patellar tendon or ACL or posterior cruciate } \\
\text { ligament).ti. }\end{array}$ & 18,599 \\
\hline 15 & 13 not 14 & 2711 \\
\hline 16 & limit 15 to (english and (article or conference paper or note or "review")) & 2038 \\
\hline 17 & limit 16 to $d c=20,180,607-20,190,710$ & 274 \\
\hline
\end{tabular}

Table 7 Search strategy The Cochrane Library

Database: The Cochrane Library

Date: $2017-02-21$

Number of results: 186 references

Cochrane reviews: 2

Other reviews: 8

Trials: 176

ID Search
\#1 hamstring or hamstrings:ti,ab,kw (Word variations have
been searched)
\#2 MeSH descriptor: [Wounds and Injuries] this term only
$\# 3$ MeSH descriptor: [Athletic Injuries] explode all trees
\#4 MeSH descriptor: [Leg Injuries] explode all trees
\#5 MeSH descriptor: [Leg Injuries] this term only
\#6 MeSH descriptor: [Sprains and Strains] this term only
\#7 MeSH descriptor: [Tendon Injuries] this term only
\#8 \#2 or \#3 or \#4 or \#5 or \#6 or \#7
\#9 injury or injuries or tear or tears or rupture or strain or
strains:ti,ab,kw (Word variations have been searched)
\#10 \#8 or \#9
\#11 \#1 and \#10
\#12 anterior cruciate ligament or "patellar tendon" or ACL or
"posterior cruciate ligament":ti (Word variations have been
searched)

\#13 \#11 not \#12

Hits

1043

1460

599

3283

177

326

5423

42, 988

44,

566

406

1551

186

Date: 2018-05-30

Number of results: 216 references

Cochrane reviews: 2
Table 7 Search strategy The Cochrane Library (Continued)

Other reviews: 8

Trials: 206

ID Search

Hits

\#1 hamstring or hamstrings:ti,ab,kw (Word variations have been searched)

\#2 MeSH descriptor: [Wounds and Injuries] this term only

\#3 MeSH descriptor: [Athletic Injuries] explode all trees

\#4 MeSH descriptor: [Leg Injuries] explode all trees

\#5 MeSH descriptor: [Leg Injuries] this term only

\#6 MeSH descriptor: [Sprains and Strains] this term only

\#7 MeSH descriptor: [Tendon Injuries] this term only

256

\#8 \#2 or \#3 or \#4 or \#5 or \#6 or \#7

6043

\#9 injury or injuries or tear or tears or rupture or strain or strains:ti,ab,kw (Word variations have been searched)

51, 335

\#10 \#8 or \#9

\#11 \#1 and \#10 "posterior cruciate ligament" searched)

\section{\#13 \#11 not \#12}

216

Date: 2019-07-10

Number of results: 102 references

Cochrane reviews: -

Other reviews: -

Trials: 102

ID Search

Hits

\#1 hamstring or hamstrings:ti,ab,kw (Word variations have been searched)

\#2 MeSH descriptor: [Wounds and Injuries] this term only

\#3 MeSH descriptor: [Athletic Injuries] explode all trees

\#4 MeSH descriptor: [Leg Injuries] explode all trees

\#5 MeSH descriptor: [Leg Injuries] this term only

\#6 MeSH descriptor: [Sprains and Strains] this term only

\#7 MeSH descriptor: [Tendon Injuries] this term only

236

\#8 \#2 or \#3 or \#4 or \#5 or \#6 or \#7

\#9 injury or injuries or tear or tears or rupture or strain or strains:ti,ab,kw (Word variations have been searched)

\#10 \#8 or \#9

\#11 \#1 and \#10 737

\#12 anterior cruciate ligament or "patellar tendon" or ACL or "posterior cruciate ligament":ti (Word variations have been searched)

\#13 \#11 not \#12

\#14 \#11 not \#13 with Cochrane Library publication date Between May 2018 and Aug 2019 
Table 8 Modified Downs and Black checklist

\section{Reporting}

1. Is the hypothesis/aim/objective of the study clearly described? 0-1p

2. Are the main outcomes to be measured clearly described in the Introduction or Methods section? 0-1p

3. Are the characteristics of the patients included in the study clearly described? 0-1p

6. Are the main findings of the study clearly described? 0-1p

7. Does the study provide estimates of the random variability in the data for the main outcomes? 0-1p

9. Have the characteristics of patients lost to follow-up been described? 0-1p

10. Have actual probability values been reported (e.g. 0.035 rather than $<0.05$ ) for the main outcomes except where the probability value is less than $0.001 ?$ ? $-1 p$

External validity

11. Were the subjects asked to participate in the study representative of the entire population from which they were recruited? $0-1 p$

12. Were those subjects who were prepared to participate representative of the entire population from which they were recruited? $0-1 p$

Internal validity - bias

16. If any of the results of the study were based on "data dredging", was this made clear? 0-1p

17. In trials and cohort studies, do the analyses adjust for different lengths of follow-up of patients, or, in case-control studies, is the time period between the intervention and outcome the same for cases and controls? 0-1p

18. Were the statistical tests used to assess the main outcomes appropriate? 0-1p

20. Were the main outcome measures used accurate (valid and reliable)? 0-1p

Internal validity - confounding

25. Was there adequate adjustment for confounding in the analyses from which the main findings were drawn? 0-1p

26. Were losses of patients to follow-up taken into account? 0-1p

Power

27. Did the study have sufficient power to detect a clinically important effect where the probability value for a difference being due to chance is less than $5 \%$ ? 0-5p

Table 9 Summary of included studies stratified by results and methods used to evaluate injury mechanism

\begin{tabular}{|c|c|c|c|c|c|c|}
\hline Authors & $\begin{array}{l}\text { Subjects } \\
\text { (n) }\end{array}$ & Aim/purpose & Methods & ${ }^{b} \mathrm{D} \& \mathrm{~B}$ & Results & Conclusion \\
\hline \multicolumn{7}{|c|}{ Passive tension injuries } \\
\hline $\begin{array}{l}\text { Askling et al. } \\
{[19]^{a}}\end{array}$ & 15 & $\begin{array}{l}\text { Investigate the injury } \\
\text { mechanism, location and } \\
\text { other factors related to } \\
\text { acute, first-time hamstring } \\
\text { injuries in dancers. }\end{array}$ & $\begin{array}{l}\text { Interview, clinical and MRI } \\
\text { examination. }\end{array}$ & 11 & $\begin{array}{l}\text { Injury occurred while } \\
\text { performing a slow-hip } \\
\text { flexion with the knee ex- } \\
\text { tended in all cases. The lo- } \\
\text { cation of injuries was close } \\
\text { to the ischial tuberosity } \\
\text { and most commonly af- } \\
\text { fected the SM (87\%), quad- } \\
\text { ratus femoris (87\%) and } \\
\text { adductor magnus (33\%). } \\
\text { There were no significant } \\
\text { findings in clinical or MRI } \\
\text { examinations to determine } \\
\text { return to preinjury level. }\end{array}$ & $\begin{array}{l}\text { Stretching movements } \\
\text { with simultaneous hip } \\
\text { flexion and knee extension } \\
\text { can cause a specific type of } \\
\text { hamstring injury. }\end{array}$ \\
\hline $\begin{array}{l}\text { Askling et al. } \\
{[31]^{a}}\end{array}$ & 30 & $\begin{array}{l}\text { Continued investigation of } \\
\text { the injury location and } \\
\text { recovery time for } \\
\text { hamstring injuries in } \\
\text { dancers. }\end{array}$ & $\begin{array}{l}\text { Interview, clinical and MRI } \\
\text { examination. }\end{array}$ & 10 & $\begin{array}{l}\text { In all cases, injury occurred } \\
\text { close to the ischial } \\
\text { tuberosity while the hip } \\
\text { was flexed and the knee } \\
\text { extended, most commonly } \\
\text { in the SM. } 47 \% \text { of the } \\
\text { subjects ended their sports } \\
\text { activity and there was no } \\
\text { significant parameter } \\
\text { during clinical or MRI }\end{array}$ & $\begin{array}{l}\text { Extensive hip flexion with } \\
\text { the knee extended can } \\
\text { cause a specific type of } \\
\text { hamstring injury near the } \\
\text { ischial tuberosity. }\end{array}$ \\
\hline
\end{tabular}


Table 9 Summary of included studies stratified by results and methods used to evaluate injury mechanism (Continued)

\begin{tabular}{lllll}
\hline Authors & Subjects Aim/purpose Methods & b D\&B Results & Conclusion
\end{tabular}

(n)

Sallay et al. $\quad 12$

Sallay
[45]

Kinematic studies

Hanley et al. 17 [35]

Heiderscheit 1

et al. [37]

Fiorentino

et al. [32]
Define the injury mechanism and present pathological changes, functional limitations and preventive measures in water skiers.
Interview, clinical examination. In five cases, $\mathrm{MRI}$ and in one CT scan. examinations to predict time until return to sport.

8 The situation varied although injury occurred due to extensive hip flexion with an extended knee. The injuries were located proximal to the posterior thigh and time until return to sport varied from three months to 1.5 years.

Analyse the work done by the lower limb in worldclass race walkers.

Most energy was and flexors of the hip and

$\begin{array}{ll}\begin{array}{l}\text { Higashihara } 8 \\ \text { et al. [39] }\end{array} & \begin{array}{l}\text { To investigate differences } \\ \text { in hamstring muscle } \\ \text { kinematics during } \\ \text { sprinting with different } \\ \text { positions of the trunk }\end{array}\end{array}$

Mann et al. $\quad 15$ $[28]^{a}$ knowledge of the
Race walking on a $45 \mathrm{~m}$ long track, with force plates to measure ground reaction forces, at competition speeds, captured at $100 \mathrm{~Hz}$.
Identify the time of injury in the gait cycle and the associated biomechanics of a hamstring injury.

To create and validate a model of the BFIh from MRI-obtained information to predict local tissue strain during sprinting.
Thirty-four reflective markers while running on a treadmill captured at 120 $\mathrm{Hz}$. Toe markers were used to determine ground contact.

A model of the biceps femoris long head was made after measuring dimensions using an MRI camera. The model was validated and then used to perform a forward dynamic simulation of sprinting at different speeds.

Thirty-four reflective markers captured at $200 \mathrm{~Hz}$ while the subjects ran two maximum-effort sprints, one with forward trunk lean and the other with an upright posture. generated by the extensors during the late stance phase from the ankle plantarflexors. The knee flexors performed the most negative work and absorbed energy during the swing phase.

Based on the first signs of injury, 130 ms of the late swing phase was where the injury occurred. Moreover, during this phase, the biceps femoris reached peak musculotendon length.

By comparing in-vivo tissue strain from dynamic MRI experiments, the model used was shown to be working. Sprinting simulations showed the highest tissue strain in the BFlh at the proximal tendinous junctions which increased with increased sprinting speed.

The forward trunk lean showed higher musculotendon length during the stance phase than upright running. Moreover, the late stance phase showed the highest positive musculotendon lengthening velocity with significantly higher values during the forward trunk lean.

Subjects were marked at anatomical landmarks and then had $40 \mathrm{~m}$ to reach kinematics during the ground phase of running.
During the stance phase, hip extensors performed concentric work from touchdown into the midsupport phase where activity shifted to the hip flexors which performed eccentric work through take-off. Muscles around the knee were dominated by flexors
Rapid stretching of the hamstrings can cause a hamstring injury.

Injury is most likely to occur during the swing phase due to the negative work performed here which is increased by the straight knee during the first half of the stance phase.

The biceps femoris is probably injured during the late swing phase due to eccentric workload.

The performed simulations showed non-uniform strain of the local fibres of the Bflh during the late swing phase which was predicted to increase with increased running speed.

Sprinting with a forward trunk lean causes the hamstrings to be more susceptible to injury during the stance phase.

Injury may occur because of the large forces working on the hamstrings when the foot touches the ground. being filmed at 150

frames/second. At least three trials/person. 
Table 9 Summary of included studies stratified by results and methods used to evaluate injury mechanism (Continued)

Authors

Subjects Aim/purpose

(n)

Schache et al. 1 [46]

Schache et al. 1 [47]

$\begin{array}{lll}\text { Sun et al. [51] } 8 \quad & \begin{array}{l}\text { Investigate hamstring } \\ \text { kinematics and load in } \\ \text { sprinting. }\end{array} \\ & \\ \text { Thelen et al. } \quad 14 \quad \begin{array}{l}\text { Help understand the } \\ \text { hamstring injury } \\ \text { mechanism by } \\ \text { investigating the work of } \\ \text { the hamstrings in } \\ \text { sprinting. }\end{array}\end{array}$

Wan et al. $\quad 20$

[53]
Compare the work performed by the different hip extensors and knee flexors during sprinting, as well as investigating asymmetries. Moreover, to compare the load on the hamstrings in different movements and before and after an injury.

Investigate asymmetries before, the biomechanical response to and timing of an injury.
Thirty-six reflective markers 8 captured at $120 \mathrm{~Hz}$ while running at different speeds on a track containing force plates before suffering a hamstring injury on the 10th sprint

A previously injured athlete 8 ran nine $30 \mathrm{~m}$ sprints with reflective markers mounted on him, while captured at $120 \mathrm{~Hz}$, on a running track with two force plates before suffering a hamstring injury on the tenth sprint.

Isokinetic strength was measured before sprint trials. Fifty-seven reflective markers on anatomical landmarks. Captured at $300 \mathrm{~Hz}$ during three to four maximum-effort sprints on a track. GRF through force plates.

Forty-seven reflective markers on anatomical landmarks. Running on a treadmill at different speeds recorded at $200 \mathrm{~Hz}$.
During both the initial stance and late swing phase, the hamstrings were subject to increased loading through forces working in opposite directions when the hip was extending and the knee flexing at the same time.

The peak length of the hamstrings was measured during the late swing phase with the biceps femoris being significantly higher and occurring later than the other muscles in the hamstring muscle group. However, no significant difference was found depending on sprinting speeds.

To investigate whether Flexibility was measured hamstring flexibility relates with a passive straight leg to peak hamstring muscle raise after a sufficient strain during sprinting. warm-up. Sprinting kinematics were measured with reflective markers on anatomical landmarks and filmed at 200 frames/second while performing 20$25 \mathrm{~m}$ sprints. Bilateral isokinetic strength tests were
Peak muscle strain of all the hamstring muscles were recorded during the late swing phase and correlated negatively to hamstring flexibility. No gender differences were recorded. The strain in the BFlh and ST was higher than in the SM.
Because of the eccentric work performed during terminal swing, the hamstrings are most probably injured in this phase.

Conclusion 
Table 9 Summary of included studies stratified by results and methods used to evaluate injury mechanism (Continued)

\begin{tabular}{lllll}
\hline Authors & Subjects & Aim/purpose & Methods & b D\&B Results
\end{tabular}

also performed.

Kinematic studies with EMG analyses

\begin{tabular}{|c|c|c|c|}
\hline $\begin{array}{l}\text { Chumanov } \\
\text { et al. [34] }\end{array}$ & 12 & $\begin{array}{l}\text { Compare the hamstring } \\
\text { mechanics in the swing } \\
\text { and stance phase during } \\
\text { sprinting. }\end{array}$ & $\begin{array}{l}\text { Forty-five reflective markers } \\
\text { along with surface } \\
\text { electrodes, the latter } \\
\text { placed on seven muscles } \\
\text { of the lower right } \\
\text { extremity, were mounted } \\
\text { on the subjects before } \\
\text { running on a treadmill at } \\
\text { different speeds. }\end{array}$ \\
\hline $\begin{array}{l}\text { Hanley et al. } \\
{[36]}\end{array}$ & 20 & $\begin{array}{l}\text { To investigate the lower } \\
\text { extremity during race } \\
\text { walking. }\end{array}$ & $\begin{array}{l}\text { Race walking on a } 45 \mathrm{~m} \\
\text { track at competitive speed } \\
\text { while filmed at } 100 \mathrm{~Hz} \text { and } \\
\text { walking over force plates } \\
\text { with surface electrodes on } \\
\text { seven muscles of the lower } \\
\text { right extremity. }\end{array}$ \\
\hline
\end{tabular}

Higashihara 13 et al. [38]

Montgomery 30 III et al. [33] ${ }^{a}$

Investigate EMG activity of muscles around the hip and knee while running at different speeds.

Investigate the hamstring injury mechanism by analysing peak musculotendon length and EMG activity during sprinting.

9
Forty $m$ acceleration was allowed on a synthetic track. Thirty-four reflective markers captured at 200 $\mathrm{Hz}$. Surface electrodes on the muscle bellies of BFlh and ST with one on the fibular head for reference.

Needle electrodes were placed in three to eight muscles before performing runs at self-determined speeds in front of a highspeed camera.
Hip extensors during late swing and early stance along with ankle plantarflexors during late stance were the most important in producing energy. Great negative work was seen by knee flexors during the swing phase.

For the biceps femoris, the maximum length and peak EMG activity occurred at the same time during the late swing phase. For the ST, the highest EMG activity was measured before it reached its maximum length.

The quadriceps had its major activity during the early stance as knee extensors, hamstrings were active in both knee flexion and hip extension during two to three periods of the gait cycle. Hip flexion was mainly performed by the rectus femoris during stance and iliacus during early-middle swing.

Ono et al. $\quad 12$ [41]

Investigate when a hamstring injury occurs by estimating tensile force during sprinting.

Padulo et al. 12 [42]
Investigate the hamstring during movements with different types of muscle contraction.
Reflective markers, high8 and surface electrodes were used to sample data from the subjects while running at maximum speeds on a $50 \mathrm{~m}$ track. A maximum voluntary contraction was used as an EMG reference.

Biceps femoris EMG activity 8 was measured by surface electrodes and subjects were filmed with a highspeed camera while performing a countermovement jump, squat jump and landing from a $45 \mathrm{~cm}$ high box. A maximum voluntary contraction was used as a
Peak values for strain of the hamstring were shown during late swing with the highest values in the ST. The BFlh peak EMG activity took place directly after the foot touched the ground.

When comparing a

A pure eccentric or counter-movement jump with a squat jump and the braking phase of a landing, the biceps femoris showed lower activation, in both the concentric and eccentric phases of the countermovement jump. stance phase. gives rise to higher exercise.
The late swing phase is more injury prone than the stance phase during sprinting.

The risk of injury to the hamstrings is highest during the swing phase, due to the negative work performed there.

The hamstrings are most likely to be injured during the late swing phase while sprinting.

The hamstrings are injured during the swing phase due to eccentric contraction, but the different muscles of the hamstring muscle group are not susceptible at exactly the same time.

The BFlh is most likely to be injured during the early concentric movement neuromuscular activity than a stretch-shortening 
Table 9 Summary of included studies stratified by results and methods used to evaluate injury mechanism (Continued)

\begin{tabular}{llll}
\hline Authors & $\begin{array}{l}\text { Subjects } \\
\text { (n) }\end{array}$ & Aim/purpose & Methods \\
\hline & & & $\begin{array}{l}\text { reference value for the } \\
\text { EMG. }\end{array}$ \\
Prior et al. & 22 & $\begin{array}{l}\text { Investigate how trunk and } \\
\text { pelvis positions affect the } \\
\text { muscles of the thigh and } \\
\text { hip while standing on one }\end{array}$ & $\begin{array}{l}\text { Markers, high-speed cam- } \\
\text { erast different muscles on } \\
\text { leg. }\end{array}$ \\
& & $\begin{array}{l}\text { both body halves was } \\
\text { measured with the subject } \\
\text { standing on one leg in dif- } \\
\text { ferent posture and pelvic } \\
\text { positions. }\end{array}$
\end{tabular}

Ruan et al. $\quad 12 \quad \begin{aligned} & \text { Investigate the effect of } \\ & \text { static stretching on } \\ & \text { hamstring injury risk. }\end{aligned}$

Schache et al. 7

[48]

Yu et al. [54] 20

\section{Strength-related injuries}

Jones et al. $\quad 20$ [40]
Investigate hamstring kinematics and activation to obtain knowledge of the hamstring injury mechanism.
Surface EMG, reflective markers, high-speed cameras and force plates collected data to compare parameters before and after a passive static stretch of the hamstrings.

Investigate the loading of the different muscles of the hamstring muscle group during sprinting.
Surface electrodes were placed on the dominant semimembranosus and biceps femoris along with bilateral reflective markers before maximum sprints were performed on an indoor track.

When comparing anterior with posterior trunk sway during a one-legged stance, the muscles situated in a posterior position in the sagittal plane increased their activity as the anterior muscles decreased their activity. When swaying to the opposite side compared with the same side as the stance leg, the lateral hip abductor activity increased. A lateral drop of the pelvis, compared with a rise, reduced hip abductor activity while the hamstring, adductor longus and vastus lateralis increased their activity.

The static stretch increased maximum BFlh length without affecting knee flexion torque. It also reduced peak GRF during the early stance phase and hamstring activation during the late swing phase.

All hamstring muscles reached their peak values regarding strain and force produced during terminal swing where they also performed negative work. The highest strain was found in the BFlh, the greatest lengthening velocity was found in ST and the highest force was found to be produced by SM which also performed the most work, both negative and positive.

During both the late stance and late swing phase, the hamstring contracted eccentrically.

The eccentric contraction speed showed a significantly higher peak value during the late swing. However, the peak value musculotendon lengths were significantly higher during the late stance.

Investigate how fatigue affects muscle strength in football players from Africa.
Athletes performed a maximum concentric knee extension and maximum eccentric knee flexion
The workout protocol generated significantly lower concentric quadriceps and eccentric
Trunk and pelvic positions affect the activation of the muscles around the hip and may increase the risk of injury.

Conclusion 
Table 9 Summary of included studies stratified by results and methods used to evaluate injury mechanism (Continued)

Authors Subjects Aim/purpose Methods $\quad{ }^{b}$ D\&B Results

(n)

$\begin{array}{ll}\text { before, during and after a } & \text { hamstring strength. } \\ \text { workout protocol that } & \text { Moreover, the ratio } \\ \text { simulates the fatigue of a } & \text { between them (eccentric } \\ \text { football game. } & \text { hamstring:concentric } \\ & \text { quadriceps) decreased } \\ & \text { significantly. }\end{array}$

Schuermans $54 \quad$ Investigate how et al. [49] synergistic work by muscles of the hamstring muscle group affects hamstring injuries.

Twenty-seven uninjured and 27 previously injured athletes underwent an MRI scan of the hamstring before and after an eccentric exercise. had a significantly more symmetrical muscle recruitment which corresponds to less economic muscle
The formerly injured group activation. Moreover, the group that had previously suffered an injury showed lower eccentric strength endurance.

Schuermans 54 et al. [50]
To identify the risk of future hamstring injuries with the help of mfMRI.
All players underwent an mfMRI scan before and after an eccentric hamstring exercise. Hamstring injuries were then registered for the following 1.5 seasons.
11

A first-time hamstring injury was associated with a high metabolic response and a proportionally higher biceps femoris contribution. A re-injury was associated with lower eccentric hamstring endurance.
Hamstring injuries may be related to the synergistic recruitment of the different muscles.

An increase in the metabolic activity of the BF is predictive of sustaining an index hamstring injury. Concerning re-injuries, lower eccentric endurance capacity is able to predict a recurrent hamstring injury.

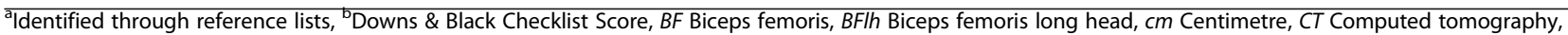
EMG Electromyography, GRF Ground reaction force, $\mathrm{Hz}$ Hertz, M Metre, MRI Magnetic resonance imaging, $\mathrm{mfMRI}$ Muscle functional magnetic resonance imaging, Ms. Milliseconds, ST Semitendinosus, SM Semimembranosus

\section{Abbreviations}

BFlh: Long head of the biceps femoris; SM: Semimembranosus; EMG: Electromyography; MRI: Magnetic resonance imaging; mfMRI: Muscle functional magnetic resonance imaging; ST: Semitendinosus; N/A: Not applicable; GRF: Ground reaction force

\section{Acknowledgments}

Therese Svanberg, at Sahlgrenska University Hospital library, has our deepest gratitude for helping with the electronic database search for this systematic review. Jeanette Kliger provided invaluable linguistic expertise.

\section{Authors' contributions}

$A D, A H, C S, E H S$ and $K S$ contributed substantially to the acquisition of the data and the analysis of the data and are responsible for drafting the work and revising it critically for important intellectual content. EAG, WEG and RC provided valuable comments and contributed from the first draft to the finished article. All the authors have given their final approval for the manuscript to be published. In addition, all the authors agree to be accountable for all aspects of the work in ensuring that questions related to the accuracy or integrity of any part of the work are appropriately investigated and resolved.

\section{Funding}

No funding was received for this study. Open Access funding provided by Gothenburg University Library.

\section{Availability of data and materials}

All data generated or analysed during this study are included in this published article [and its supplementary information files].

\section{Ethics approval and consent to participate}

Not applicable.

\section{Consent for publication}

Not applicable.

\section{Competing interests}

None declared.

\section{Author details}

${ }^{1}$ Department of Orthopaedics, Sahlgrenska University Hospital, Mölndal, Sweden. 'Department of Orthopaedics, Institute of Clinical Sciences, Sahlgrenska Academy, University of Gothenburg, Göteborgsvägen 31, SE-431 80 Mölndal, Gothenburg, Sweden. ${ }^{3}$ Department of Internal Medicine and Clinical Nutrition, Institution of Medicine, Sahlgrenska Academy, University of Gothenburg, Gothenburg, Sweden. ${ }^{4}$ Instituto Cugat, Barcelona, Spain. ${ }^{5}$ Mutualidad Catalana de Futbolistas, Federación Española de Fútbol, Barcelona, Spain. ${ }^{6}$ Fundación García-Cugat, Barcelona, Spain. ${ }^{7}$ Duke Sports Sciences Institute, Duke University, Durham, North Carolina, USA. ${ }^{8}$ Department of Health and Rehabilitation, Institute of Neuroscience and Physiology, Sahlgrenska Academy, University of Gothenburg, Gothenburg, Sweden.

Received: 6 June 2020 Accepted: 18 September 2020

Published online: 29 September 2020

\section{References}

1. Ekstrand J, Walden M, Hagglund M. Hamstring injuries have increased by 4\% annually in men's professional football, since 2001: a 13-year longitudinal analysis of the UEFA elite Club injury study. Br J Sports Med. 2016;50(12):731-7.

2. Hagel B. Hamstring injuries in Australian football. Clin J Sport Med. 2005; 15(5):400.

3. Roe M, Murphy JC, Gissane C, Blake C. Hamstring injuries in elite Gaelic football: an 8-year investigation to identify injury rates, time-loss patterns and players at increased risk. Br J Sports Med. 2016;52(15):982-8.

4. Edouard $\mathrm{P}$, Branco $\mathrm{P}$, Alonso JM. Muscle injury is the principal injury type and hamstring muscle injury is the first injury diagnosis during top-level international athletics championships between 2007 and 2015. Br J Sports Med. 2016;50(10):619-30.

5. Ahmad CS, Dick RW, Snell E, Kenney ND, Curriero FC, Pollack K, et al. Major and minor league baseball hamstring injuries: epidemiologic findings from 
the Major League Baseball injury surveillance system. Am J Sports Med. 2014;42(6):1464-70.

6. Hickey J, Shield AJ, Williams MD, Opar DA. The financial cost of hamstring strain injuries in the Australian football league. Br J Sports Med. 2014;48(8): 729-30

7. Rinonapoli G, Graziani M, Ceccarini P, Razzano C, Manfreda F, Caraffa A. Epidemiology of injuries connected with dance: a critical review on epidemiology. Med Glas (Zenica). 2020;17(2):256-64.

8. Engebretsen AH, Myklebust G, Holme I, Engebretsen L, Bahr R. Intrinsic risk factors for hamstring injuries among male soccer players: a prospective cohort study. Am J Sports Med. 2010;38(6):1147-53.

9. Hagglund $\mathrm{M}$, Walden $\mathrm{M}$, Ekstrand J. Previous injury as a risk factor for injury in elite football: a prospective study over two consecutive seasons. $\mathrm{Br} J$ Sports Med. 2006;40(9):767-72.

10. Croisier JL, Ganteaume S, Binet J, Genty M, Ferret JM. Strength imbalances and prevention of hamstring injury in professional soccer players: a prospective study. Am J Sports Med. 2008;36(8):1469-75.

11. Askling C, Karlsson J, Thorstensson A. Hamstring injury occurrence in elite soccer players after preseason strength training with eccentric overload. Scand J Med Sci Sports. 2003;13(4):244-50.

12. Petersen J, Thorborg K, Nielsen MB, Budtz-Jorgensen E, Holmich P. Preventive effect of eccentric training on acute hamstring injuries in men's soccer: a cluster-randomized controlled trial. Am J Sports Med. 2011;39(11): 2296-303.

13. Hartig DE, Henderson JM. Increasing hamstring flexibility decreases lower extremity overuse injuries in military basic trainees. Am J Sports Med. 1999; 27(2):173-6.

14. Mason DL, Dickens VA, Vail A. Rehabilitation for hamstring injuries. Cochrane Database Syst Rev. 2012;12:CD004575.

15. Pas HI, Reurink G, Tol JL, Weir A, Winters M, Moen MH. Efficacy of rehabilitation (lengthening) exercises, platelet-rich plasma injections, and other conservative interventions in acute hamstring injuries: an updated systematic review and meta-analysis. Br J Sports Med. 2015;49(18):1197-205.

16. Askling CM, Malliaropoulos N, Karlsson J. High-speed running type or stretching-type of hamstring injuries makes a difference to treatment and prognosis. Br J Sports Med. 2012;46(2):86-7.

17. Askling C, Saartok T, Thorstensson A. Type of acute hamstring strain affects flexibility, strength, and time to return to pre-injury level. Br J Sports Med. 2006;40(1):40-4

18. Askling CM, Tengvar M, Saartok T, Thorstensson A. Acute first-time hamstring strains during high-speed running: a longitudinal study including clinical and magnetic resonance imaging findings. Am J Sports Med. 2007; 35(2):197-206

19. Askling CM, Tengvar M, Saartok T, Thorstensson A. Acute first-time hamstring strains during slow-speed stretching: clinical, magnetic resonance imaging, and recovery characteristics. Am J Sports Med. 2007;35(10):1716-24.

20. Woods C, Hawkins RD, Maltby S, Hulse M, Thomas A, Hodson A. The football association medical research Programme: an audit of injuries in professional football - analysis of hamstring injuries. Br J Sports Med. 2004; 38(1):36-41.

21. Verrall GM, Slavotinek JP, Barnes PG, Fon GT. Diagnostic and prognostic value of clinical findings in 83 athletes with posterior thigh injury. Comparison of clinical findings with magnetic resonance imaging documentation of hamstring muscle strain. Am J Sports Med. 2003;31(6): 969-73.

22. Garrett WE Jr. Muscle strain injuries. Am J Sports Med. 1996;24(SUPPL):S2-8

23. Lieber RL, Friden J. Muscle damage is not a function of muscle force but active muscle strain. J Appl Physiol. 1993;74(2):520-6.

24. Chumanov ES, Schache AG, Heiderscheit BC, Thelen DG. Hamstrings are most susceptible to injury during the late swing phase of sprinting. $\mathrm{Br} J$ Sports Med. 2012;46(2):90.

25. Al Attar WS, Soomro N, Sinclair PJ, Pappas E, Sanders RH. Effect of injury prevention programs that include the Nordic hamstring exercise on hamstring injury rates in soccer players: a systematic review and metaanalysis. Sports Med. 2016:47(5):907-16.

26. Seagrave RA, Perez L, McQueeney S, Bruce Toby E, Key V, Nelson JD. Preventive effects of eccentric training on acute hamstring muscle injury in professional baseball. Orthop J Sports Med. 2014;2(6):2325967114535351.

27. van der Horst N, Smits DW, Petersen J, Goedhart EA, Backx FJ. The preventive effect of the nordic hamstring exercise on hamstring injuries in amateur soccer players: a randomized controlled trial. Am J Sports Med. 2015;43(6):1316-23.

28. Mann R, Sprague P. A kinetic analysis of the ground leg during sprint running. Res Q Exerc Sport. 1980;51(2):334-48.

29. Moher D, Liberati A, Tetzlaff J, Altman DG. Preferred reporting items for systematic reviews and meta-analyses: the PRISMA statement. PLoS Med. 2009;6(7):e1000097.

30. Downs SH, Black N. The feasibility of creating a checklist for the assessment of the methodological quality both of randomised and non-randomised studies of health care interventions. J Epidemiol Community Health. 1998; 52(6):377-84.

31. Askling CM, Tengvar M, Saartok T, Thorstensson A. Proximal hamstring strains of stretching type in different sports: injury situations, clinical and magnetic resonance imaging characteristics, and return to sport. Am J Sports Med. 2008;36(9):1799-804.

32. Fiorentino NM, Rehorn MR, Chumanov ES, Thelen DG, Blemker SS Computational models predict larger muscle tissue strains at faster sprinting speeds. Med Sci Sports Exerc. 2014;46(4):776-86.

33. Montgomery IWH, Pink M, Perry J. Electromyographic analysis of hip and knee musculature during running. Am J Sports Med. 1994;22(2):272-8.

34. Chumanov ES, Heiderscheit BC, Thelen DG. Hamstring musculotendon dynamics during stance and swing phases of high-speed running. Med Sci Sports Exerc. 2011:43(3):525-32.

35. Hanley B, Bissas A. Analysis of lower limb work-energy patterns in worldclass race walkers. J Sports Sci. 2017:35(10):960-6.

36. Hanley B, Bissas A. Analysis of lower limb internal kinetics and electromyography in elite race walking. J Sports Sci. 2013;31(11):1222-32.

37. Heiderscheit BC, Hoerth DM, Chumanov ES, Swanson SC, Thelen BJ, Thelen DG. Identifying the time of occurrence of a hamstring strain injury during treadmill running: a case study. Clin Biomech. 2005;20(10):1072-8.

38. Higashihara A, Nagano Y, Ono T, Fukubayashi T. Relationship between the peak time of hamstring stretch and activation during sprinting. Eur J Sport Sci. 2016;16(1):36-41.

39. Higashihara A, Nagano Y, Takahashi K, Fukubayashi T. Effects of forward trunk lean on hamstring muscle kinematics during sprinting. J Sports Sci. 2015;33(13):1366-75

40. Jones Rl, Ryan B, Todd Al. Muscle fatigue induced by a soccer match-play simulation in amateur Black south African players. J Sports Sci. 2015;33(12): 1305-11.

41. Ono T, Higashihara A, Shinohara J, Hirose N, Fukubayashi T. Estimation of tensile force in the hamstring muscles during overground sprinting. Int J Sports Med. 2015;36(2):163-8.

42. Padulo J, Tiloca A, Powell D, Granatelli G, Bianco A, Paoli A. EMG amplitude of the biceps femoris during jumping compared to landing movements. SpringerPlus. 2013;2:520.

43. Prior S, Mitchell T, Whiteley R, O'Sullivan P, Williams BK, Racinais $\mathrm{S}$, et al. The influence of changes in trunk and pelvic posture during single leg standing on hip and thigh muscle activation in a pain free population. BMC Sports Sci Med Rehabil. 2014;6(1):13.

44. Ruan $M, L i L, C h e n C$, Wu X. Stretch could reduce hamstring injury risk during sprinting by right shifting the length-torque curve. J Strength Cond Res. 2018;32(8):2190-8.

45. Sallay PI, Friedman RL, Coogan PG, Garrett WE. Hamstring muscle injuries among water skiers. Functional outcome and prevention. Am J Sports Med. 1996;24(2):130-6.

46. Schache AG, Kim HJ, Morgan DL, Pandy MG. Hamstring muscle forces prior to and immediately following an acute sprinting-related muscle strain injury. Gait Posture. 2010;32(1):136-40.

47. Schache AG, Wrigley TV, Baker R, Pandy MG. Biomechanical response to hamstring muscle strain injury. Gait Posture. 2009;29(2):332-8.

48. Schache AG, Dorn TW, Blanch PD, Brown NAT, Pandy MG. Mechanics of the human hamstring muscles during sprinting. Med Sci Sports Exerc. 2012; 44(4):647-58.

49. Schuermans J, Van Tiggelen D, Danneels L, Witvrouw E. Biceps femoris and semitendinosus--teammates or competitors? New insights into hamstring injury mechanisms in male football players: a muscle functional MRI study. Br J Sports Med. 2014;48(22):1599-606.

50. Schuermans J, Van Tiggelen D, Danneels L, Witvrouw E. Susceptibility to hamstring injuries in soccer: a prospective study using muscle functional magnetic resonance imaging. Am J Sports Med. 2016;44(5):1276-85. 
51. Sun Y, Wei S, Zhong Y, Fu W, Li L, Liu Y. How joint torques affect hamstring injury risk in sprinting swing-stance transition. Med Sci Sports Exerc. 2015; 47(2):373-80.

52. Thelen DG, Chumanov ES, Hoerth DM, Best TM, Swanson SC, Li L, et al. Hamstring muscle kinematics during treadmill sprinting. Med Sci Sports Exerc. 2005;37(1):108-14.

53. Wan X, Qu F, Garrett WE, Liu H, Yu B. The effect of hamstring flexibility on peak hamstring muscle strain in sprinting. J Sport Health Sci. 2017;6(3):283-9.

54. Yu B, Queen RM, Abbey AN, Liu Y, Moorman CT, Garrett WE. Hamstring muscle kinematics and activation during overground sprinting. J Biomech. 2008;41(15):3121-6.

55. Worth DR. The hamstring injury in Australian rules football. Aust J Physiother. 1969;15(3):111-3.

56. Kenneally-Dabrowski CJB, Brown NAT, Lai AKM, Perriman D, Spratford W, Serpell BG. Late swing or early stance? A narrative review of hamstring injury mechanisms during high-speed running. Scand J Med Sci Sports. 2019;29(8):1083-91.

57. Mendiguchia J, Edouard P, Samozino P, Brughelli M, Cross M, Ross A, et al. Field monitoring of sprinting power-force-velocity profile before, during and after hamstring injury: two case reports. J Sports Sci. 2016;34(6):535-41.

58. Daly C, Persson UM, Twycross-Lewis R, Woledge RC, Morrissey D. The biomechanics of running in athletes with previous hamstring injury: a casecontrol study. Scand J Med Sci Sports. 2016;26(4):413-20.

59. Schuermans J, Danneels L, Van Tiggelen D, Palmans T, Witvrouw E. Proximal neuromuscular control protects against hamstring injuries in male soccer players: a prospective study with electromyography time-series analysis during maximal sprinting. Am J Sports Med. 2017;45(6):1315-25.

60. Schuermans J, Van Tiggelen D, Palmans T, Danneels L, Witvrouw E. Deviating running kinematics and hamstring injury susceptibility in male soccer players: cause or consequence? Gait Posture. 2017;57:270-7.

61. Schuermans J, Van Tiggelen D, Witvrouw E. Prone hip extension muscle recruitment is associated with hamstring injury risk in amateur soccer. Int J Sports Med. 2017;38(9):696-706.

62. Bourne MN, Duhig SJ, Timmins RG, Williams MD, Opar DA, Al Najjar A, et al. Impact of the Nordic hamstring and hip extension exercises on hamstring architecture and morphology: implications for injury prevention. Br J Sports Med. 2017;51(5):469-77.

63. Timmins RG, Bourne MN, Shield AJ, Williams MD, Lorenzen C, Opar DA. Short biceps femoris fascicles and eccentric knee flexor weakness increase the risk of hamstring injury in elite football (soccer): a prospective cohort study. Br J Sports Med. 2016;50(24):1524-35.

64. van den Tillaar R, Solheim JAB, Bencke J. Comparison of hamstring muscle activation during high-speed running and various hamstring strengthening exercises. Int J Sports Phys Ther. 2017;12(5):718-27.

65. Hansen C, Einarson E, Thomson A, Whiteley R. Peak medial (but not lateral) hamstring activity is significantly lower during stance phase of running. An EMG investigation using a reduced gravity treadmill. Gait Posture. 2017;57: 7-10.

66. van Beijsterveldt AMC, van de Port IGL, Vereijken AJ, Backx FJG. Risk factors for hamstring injuries in male soccer players: a systematic review of prospective studies. Scand J Med Sci Sports. 2013;23(3):253-62.

\section{Publisher's Note}

Springer Nature remains neutral with regard to jurisdictional claims in published maps and institutional affiliations.

\section{Ready to submit your research? Choose BMC and benefit from}

- fast, convenient online submission

- thorough peer review by experienced researchers in your field

- rapid publication on acceptance

- support for research data, including large and complex data types

- gold Open Access which fosters wider collaboration and increased citations

- maximum visibility for your research: over $100 \mathrm{M}$ website views per year

At $\mathrm{BMC}$, research is always in progress.

Learn more biomedcentral.com/submissions 